\title{
Effect of Milk Formula Protein Content on Intestinal Barrier Function in a Porcine Model of LBW Neonates
}

\author{
GAËLLE BOUDRY, ANNE MORISE, BERNARD SEVE, AND ISABELLE LE HUËROU-LURON
}

Unité Mixte de Recherche 1079, Institut National de la Recherche Agronomique, Saint-Gilles F-35590, France; Unité Mixte de Recherche 1079, Agrocampus Ouest, Rennes F-35000, France

\begin{abstract}
Our study aimed at investigating the impact of the level of protein in milk formula on intestinal structure, barrier function, and its nervous regulation in normal and LBW neonates using a porcine model. Normal birth weight (NBW) or LBW piglets were fed from d7 to d28 of age either with a high protein (HP) or with an adequate protein (AP) formula or stayed with their mother [mother fed (MF)]. The proximal jejunum and distal ileum were sampled at d28 for morphometry analysis and ex vivo permeability measurement in Ussing chambers. Formula feeding induced a trophic effect on the jejunum and ileum of both NBW and LBW piglets, which exhibited longer villi than MF animals, irrespective of the type of formula. In NBW piglets, intestinal permeability was not altered by formula feeding. On the contrary, LBW piglets fed with HP formula, but not AP, exhibited a greater ileal permeability than MF piglets. Feeding the HP formula also disturbed jejunal and ileal regulation of permeability by acetylcholine and vasoactive intestinal peptide (VIP) in LBW compared with MF LBW piglets. In conclusion, the level of protein in formulas did not modify intestinal structure and function in NBW individuals but dramatically modified intestinal barrier function physiology in LBW individuals. (Pediatr Res 69: 4-9, 2011)
\end{abstract}

$\mathrm{T}_{\mathrm{t}}$ he health benefits of breast feeding have been recognized for a long time. However, many infants are still formulafed for periods of their first months of life. Formulation is an area of intensive research to improve the nutritional quality of milk formulas. However, the amount of protein per energy content is generally higher in formula than in human milk to meet the protein and amino acid requirements of infants (up to 40 and $66 \%$ more proteins than human milk for healthy neonates and preterm and LBW babies, respectively) (1). Epidemiological data point out an increased risk of developing metabolic disease and obesity later in life with accelerated growth in early life (2). High protein (HP) formulas are suspected to be one of the major factors of such accelerated growth (3). Therefore, the actual tendency is to reduce protein content in formulas toward the minimal level (4), although HP formulas are still recommended for premature and LBW babies (5).

Received April 19, 2010; accepted August 10, 2010.

Correspondence: Gaëlle Boudry, Ph.D., INRA UMR 1079 SENAH, Domaine de la Prise, F-35590 Saint-Gilles, France; e-mail: gaelle.boudry@rennes.inra.fr

Supported by the Institut National de la Recherche Agronomique (INRA) and Nestec.
Several studies have established that formula-feeding impacts intestinal development. Using endoscopic techniques to obtain biopsies from healthy infants, Thompson et al. (6) observed that crypt length was increased by $30 \%$ in formulafed infants. More extensive studies undertaken in rats also concluded to a trophic effect of formula- versus breast-feeding on the intestine $(7,8)$. Besides structural modifications, formula feeding also impacts intestinal epithelial barrier function. The epithelium lining the intestine plays an integrated role in maintaining intestinal barrier function through the proteins forming the tight junctions (TJs), which constitute a selective barrier and regulate the passage of molecules according to their size. Intestinal barrier function is partially regulated by the enteric nervous system, particularly by acetylcholine known to increase permeability (9) and vasoactive intestinal peptide (VIP) that decreases permeability (10). Measurement of intestinal permeability in vivo in human neonates consistently reveals a higher permeability in formula-fed compared with breast-fed neonates $(11,12)$. Studies in rabbits and rats corroborate this increased permeability in formula-fed animals $(13,14)$.

Modifications of intestinal permeability and structure during the neonatal period might have either immediate or longterm health consequences. Indeed, during the neonatal period, enhanced uptake of molecules in the intestinal mucosa may have a role in the maturation of the immune system and the acquisition of oral tolerance $(15,16)$. However, increased permeability leaves neonates more susceptible to infection, inflammation, and hypersensitivity and may also lead to a higher susceptibility to stress or inflammation later on in adult life $(17,18)$. Considering the already known effect of formula feeding on intestinal structure and barrier development in such a crucial period of life, the question of the impact of the level of protein in formulas on the intestinal development is raised. Therefore, the objective of our study was to investigate the effect of the level of protein in formula on intestinal structure and nervous regulation of intestinal barrier using the piglet model. Intestinal permeability and structure was measured in

Abbreviations: AChE, acetylcholine esterase; AP, adequate protein; CGN, cingulin; ChAT, choline acetyl transferase; FD-4, FITC-dextran 4000; HP, high protein; HRP, horseradish peroxidase; MF, mother fed; NBW, normal birth weight; TJ, tight junction; VIP, vasoactive intestinal peptide 
both normal birth weight (NBW) and LBW piglets either fed by their mother (sow milk $4.5 \mathrm{~g}$ of protein $/ 100 \mathrm{kcal}$ ) or fed by a HP formula ( $6.6 \mathrm{~g}$ of protein $/ 100 \mathrm{kcal})$ or an AP formula (4.5 $\mathrm{g}$ of protein $/ 100 \mathrm{kcal}$ ) for $21 \mathrm{~d}$.

\section{MATERIALS AND METHODS}

Animals and experimental design. The experiment was conducted in compliance with the guidelines of the French Ministry of Agriculture for Use of Animals in Research (certificate of authorization to experiment on living animals no. 7676). Crossbred [Pietrain $\times$ (Large White $\times$ Landrace)] piglets from the experimental herd of INRA (Saint-Gilles, France) were used. Two groups of NBW and LBW piglets, regardless of gender, were selected. Piglets weighing the average birth weight of the herd (range, $1.28-1.66 \mathrm{~kg} ; n=33$ ) were identified as NBW and those weighing around $1.00 \mathrm{~kg}$ (range, $0.90-1.10$ $\mathrm{kg} ; n=33$ ) were defined as LBW. Triplets of LBW or NWB littermates were selected and allowed to suckle the sow naturally until the age of $7 \mathrm{~d}$. Piglets from the same triplets were then randomly assigned to three dietary groups. Piglets from the first group were mother fed (MF) until the age of 28 d. Piglets from the two other groups were separated from their mother and fed with either a HP formula or an AP formula until d 28. Piglets were killed at the end of this experimental period. Piglets were fed with formulas with an automatic milk feeder as described previously (19). The AP and HP formula composition are presented in Table 1. For the comparison with formula-fed piglets that were submitted to an overnight fast, the MF piglets were separated from the sow between 2130 and $0600 \mathrm{~h}$. Piglets of the three groups had free access to water and none had access to any solid food.

Tissue collection. Piglets were killed $3 \mathrm{~h}$ after their last meal by electronarcosis immediately followed by exsanguination. The digestive tract was dissected. Empty stomach, empty small intestine and colon, and pancreas and liver were weighed. Small intestine and colon length were recorded. The proximal jejunum (starting orally $20 \mathrm{~cm}$ after the Treitz ligament) and the distal ileum (starting aborally $20 \mathrm{~cm}$ from the ileocecal valvula) were dissected. For each intestinal site, a 50-cm segment was emptied, flushed with cold saline, and gently dried. Mucosa scrapings were then snap frozen and stored at $-20^{\circ} \mathrm{C}$ for further digestive enzyme analysis. A 5 -cm adjacent segment was emptied, flushed with cold saline, and fixed in $4 \%$ paraformaldehyde for $24 \mathrm{~h}$ then stored in $75 \%$ ethanol for further morphometry analysis. One-centimeter segments were also rinsed with cold saline and placed into RNA later (Applied Biosystems, Courbaboeuf, France) at $4^{\circ} \mathrm{C}$ for $24 \mathrm{~h}$ and then maintained at $-20^{\circ} \mathrm{C}$ for later RT-PCR analysis. Finally, a $20-\mathrm{cm}$ segment was flushed with cold saline and immediately placed in Ringer's bicarbonate solution (composition in $\mathrm{mmol} \cdot \mathrm{L}^{-1}: \mathrm{Na}^{+} 145, \mathrm{Cl}^{-} 128, \mathrm{PO}_{4}{ }^{3-}$ $0.32, \mathrm{Ca}^{2+} 2, \mathrm{Mg}^{2+} 1, \mathrm{HCO}_{3}{ }^{-} 25, \mathrm{SO}_{4}{ }^{2-} 1, \mathrm{~K}^{+} 6.3, \mathrm{pH}$ 7.4) for Ussing chamber permeability studies.

Morphometry analysis. Villi length and crypt depth were determined on hematoxylin-eosin-stained jejunal and ileal sections. A minimum of 15 to 20 well-oriented crypt-villus units was measured using image analysis (Optimas, version 6.5; Media Cybernetics, L.P., Silver Spring). All morphological measurements were conducted by one investigator who was unaware of the piglet group from which the section was prepared.

Enzyme activity. The specific activities of amino-peptidase N (EC 3.4.11.2), lactase-phlorizine hydrolase (EC 3.2.1.23), and dipeptidyl peptidase IV (EC 3.4.14.5) were determined in the jejunum and ileum as previously described (20). Acetylcholine esterase (AChE) activity was measured using a dedicated kit (Invitrogen, Cergy-Pontoise, France). The protein content of tissue homogenates was measured using the Bio-Rad protein assay reagent (Bio-Rad, France).

Ex vivo permeability. Intestinal tissues were stripped of longitudinal muscle and opened along the antimesenteric border to be mounted in Ussing chamber (World Precision Instrument, Stevenage, United Kingdom). The chamber opening exposed $0.67 \mathrm{~cm}^{2}$ of tissue surface area to $8 \mathrm{~mL}$ of circulating oxygenated Ringer at $39^{\circ} \mathrm{C}$. The serosal buffer contained 16 $\mathrm{mmol} \cdot \mathrm{L}^{-1}$ glucose osmotically balanced by $16 \mathrm{mmol} \cdot \mathrm{L}^{-1}$ mannitol in the mucosal buffer. Tissue viability was checked by recording potential difference across the tissue every $30 \mathrm{~min}$. The paracellular and transcellular passages were determined with FITC-dextran 4000 (FD-4; Sigma Chemical Co.Aldrich, Saint-Quentin Fallavier, France) and horseradish peroxidase (HRP Type II; Sigma Chemical Co.-Aldrich), respectively, as previously described $(21,22)$. FD-4 and HRP $\left(375 \mathrm{mg} . \mathrm{L}^{-1}\right.$ each) were added to the mucosal buffer at t0. Five hundred microliters samples were collected at 30-min intervals during $120 \mathrm{~min}$ from the serosal buffer and replaced with Ringer-glucose buffer to maintain a constant volume within the chambers. For LBW piglets, change in permeability to FD-4 induced by either $10^{-3} \mathrm{M}$ carbachol (cholinergic agonist; Sigma Chemical Co.-Aldrich) or $10^{-6}$ M VIP (Sigma Chemical
Table 1. Composition of sow milk and of high and adequate protein level formula

\begin{tabular}{|c|c|c|c|}
\hline & $\begin{array}{l}\text { Sow } \\
\text { milk }\end{array}$ & $\begin{array}{l}\text { High protein } \\
\text { formula }\end{array}$ & $\begin{array}{l}\text { Adequate protein } \\
\text { formula }\end{array}$ \\
\hline \multicolumn{4}{|l|}{ Ingredients (\%) } \\
\hline Whey protein & - & 18.47 & 13.27 \\
\hline Casein & - & 11.56 & 8.31 \\
\hline Skimmed milk powder & - & 12.39 & 8.90 \\
\hline Lactose & - & 11.50 & 17.47 \\
\hline Milk fat & - & 11.60 & 14.07 \\
\hline Palm olein & - & 15.27 & 17.85 \\
\hline Vegetable oil* & - & 6.88 & 8.33 \\
\hline L -Arginine & - & 0.79 & 0.56 \\
\hline L -Cystine & - & 0.12 & 0.09 \\
\hline L -Glutamic acid & - & 1.18 & 0.85 \\
\hline Glycine & - & 0.60 & 0.43 \\
\hline L -Histidine & - & 0.18 & 0.13 \\
\hline L -Proline & - & 1.85 & 1.33 \\
\hline L -Valine & - & 0.33 & 0.24 \\
\hline Vitamin $\operatorname{mix} \dagger$ & - & 0.30 & 0.30 \\
\hline Choline bitartrate & - & 0.17 & 0.17 \\
\hline Calcium phosphate, dibasic & - & 2.27 & 2.63 \\
\hline Calcium citrate, tribasic & - & 1.01 & 0.80 \\
\hline Sodium citrate, tribasic & - & 0.53 & 0.55 \\
\hline Potassium citrate, tribasic & - & 0.03 & 0.27 \\
\hline Sodium chloride & - & 0.08 & 0.15 \\
\hline Magnesium chloride & - & 0.09 & 0.10 \\
\hline Mineral mix & - & 0.30 & 0.30 \\
\hline Water & - & 2.50 & 2.90 \\
\hline \multicolumn{4}{|l|}{ Composition } \\
\hline Protein $(\mathrm{g} / \mathrm{L})$ & 50 & 74.7 & 50.5 \\
\hline Lipid (g/L) & 80 & 73 & 80 \\
\hline Lactose $(\mathrm{g} / \mathrm{L})$ & 51 & 46 & 51 \\
\hline Energy $(\mathrm{kcal} / \mathrm{L})$ & 1124 & 1136 & 1117 \\
\hline Protein/energy (g/100 kcal) & 4.5 & 6.2 & 4.5 \\
\hline
\end{tabular}

* Mix of palm, corn, canola, and sunflower oil.

$\dagger$ Providing per $100 \mathrm{~g}$ diet DM: vitamin A (retinol) $442.5 \mu \mathrm{g}$ as retinyl acetate; vitamin $\mathrm{D}_{3}$ (cholecalciferol), $10.5 \mu \mathrm{g}$; vitamin $\mathrm{E} 0.77 \mathrm{mg}$ as allracemic $\alpha$-tocopherol acetate; vitamin $\mathrm{K}_{1}$ (phylloquinone) $0.28 \mathrm{mg}$; vitamin $\mathrm{C}$ (sodium ascorbate) $75 \mathrm{mg}$; vitamin $\mathrm{B}_{1} 0.56 \mathrm{mg}$ as thiamine mononitrate, vitamin $P P$ (nicotinamide) $6 \mathrm{mg}$; vitamin $\mathrm{B}_{2}$ (riboflavin) $1.10 \mathrm{mg}$; vitamin $\mathrm{B}_{6}$ (pyridoxine) $1.10 \mathrm{mg}$, folic acid $0.21 \mathrm{mg}$, calcium pantothenate $2.65 \mathrm{mg}$; and vitamin $\mathrm{B}_{12}$ (cyanocobalamin) $2.30 \mu \mathrm{g}$, biotin $15.00 \mu \mathrm{g}$, iodine $100 \mu \mathrm{g}$ as potassium iodide.

$\$$ Providing per $100 \mathrm{~g}$ diet DM: Fe $11.9 \mathrm{mg}$ as ferrous sulphate, $\mathrm{Cu} 2.00 \mathrm{mg}$ as copper sulphate, $\mathrm{Zn} 11.60 \mathrm{mg}$ as zinc sulphate, $\mathrm{Mn} 2.99 \mathrm{mg}$ as manganese sulphate, and Se $20 \mu \mathrm{g}$ as sodium selenate.

Co.-Aldrich) added in the chamber (serosal side) were recorded. Concentration of FD-4 in the samples was measured by fluorimetry (fluorimeter LB940 Mithras; Berthold Technologies, Thoiry, France), whereas concentration of HRP was determined using spectrophotometry (Multiskan spectrum; Thermo Labsystem, Midland, Canada) after enzymatic reaction using o-dianisidine as substrate (Sigma Chemical Co.-Aldrich). Mucosal-to-serosal fluxes were then calculated and expressed as nanograms per square centimeter per hour.

$\boldsymbol{R} \boldsymbol{T}-\boldsymbol{P C R}$. Total RNA was extracted and reverse transcripted as previously described (19). Obtained cDNA were amplified using specific primers for cingulin (CGN; Fwd GTTAAAGAGCTGTCCATCCAGATTG and rev CTTAGCTGGTCTTTCTGGTCATTG), ZO-1 (Fwd AGGCGATGTTGTATTGAAGATAAATG and rev TTTTTGCATCCGTCAATGACA), and choline acetyl transferase (ChAT) genes (Fwd AGCTAGCCTTCTACAGGCTCCAT and rev CGCTCTCATAGGTAGGCACGA). The transcript level was normalized to the transcript level of GAPDH (Fwd CATCCATGACAACTTCGGCA and Rev GCATGGACTGTGGTCATGAGTC) in the same sample.

Statistical analysis. Data were analyzed using the General Linear Model procedure of Statistical Analysis Systems software (SAS Institute, Cary, NC) testing the diet effect within each birth weight group. All results are presented as mean \pm SEM. Differences between groups were declared significant at $p<$ 0.05 . 
Table 2. Piglet growth, energy intake, and characteristics of the organs of the gastrointestinal tract in MF and HP or AP formula-fed $N B W$ and $L B W$ piglets

\begin{tabular}{|c|c|c|c|c|c|c|}
\hline & \multicolumn{3}{|c|}{ NBW } & \multicolumn{3}{|c|}{ LBW } \\
\hline & MF & $\mathrm{HP}$ & AP & $\mathrm{MF}$ & $\mathrm{HP}$ & AP \\
\hline Daily weight gain/weight at d7 (g/kg) & $87 \pm 5$ & $79 \pm 13$ & $62 \pm 3^{*}$ & $96 \pm 10$ & $77 \pm 13$ & $74 \pm 5^{*}$ \\
\hline Energy intake $\left(\mathrm{kcal} / \mathrm{kg} \mathrm{BW} \mathrm{BW}^{0.75} / \mathrm{d}\right)$ & n.d. & $150 \pm 6$ & $145 \pm 5$ & n.d. & $153 \pm 8$ & $159 \pm 3$ \\
\hline Stomach weight $(\mathrm{g} / \mathrm{kg} \mathrm{BW})$ & $5.5 \pm 0.3$ & $5.8 \pm 0.2$ & $6.1 \pm 0.2$ & $6.0 \pm 0.3$ & $6.3 \pm 0.2$ & $6.4 \pm 0.3$ \\
\hline Pancreas weight $(\mathrm{g} / \mathrm{kg} \mathrm{BW})$ & $1.6 \pm 0.2$ & $1.8 \pm 0.1$ & $1.6 \pm 0.1$ & $1.4 \pm 0.1$ & $1.9 \pm 0.2^{*}$ & $1.5 \pm 0.1$ \\
\hline Liver weight $(\mathrm{g} / \mathrm{kg} \mathrm{BW})$ & $22.6 \pm 0.9$ & $26.8 \pm 0.8^{*}$ & $25.0 \pm 0.6^{*}$ & $24.6 \pm 1.4$ & $28.0 \pm 1.0 *$ & $28.7 \pm 1.6 *$ \\
\hline Small intestine length $(\mathrm{cm} / \mathrm{kg} \mathrm{BW})$ & $114 \pm 10$ & $143 \pm 6^{*}$ & $153 \pm 9 *$ & $134 \pm 10$ & $164 \pm 12 *$ & $169 \pm 10^{*}$ \\
\hline Small intestine weight $(\mathrm{g} / \mathrm{kg} \mathrm{BW})$ & $31.7 \pm 2.6$ & $40.8 \pm 2.2^{*}$ & $40.5 \pm 1.8 *$ & $35.2 \pm 2.5$ & $42.8 \pm 2.5$ & $45.0 \pm 2.0 *$ \\
\hline Jejunum musculosa density (mg/cm) & $87.6 \pm 7.7$ & $92.0 \pm 6.9$ & $87.4 \pm 3.7$ & $94.2 \pm 6.2$ & $81.4 \pm 5.2$ & $94.2 \pm 8.1$ \\
\hline Jejunum mucosa density $(\mathrm{mg} / \mathrm{cm})$ & $193.5 \pm 18.8$ & $246.9 \pm 16.1^{*}$ & $211.9 \pm 13.4$ & $156.7 \pm 23.6$ & $207.5 \pm 16.1^{*}$ & $192.9 \pm 13.2$ \\
\hline Ileum musculosa density $(\mathrm{mg} / \mathrm{cm})$ & $110.6 \pm 9.6$ & $124.0 \pm 13.2$ & $110.0 \pm 7.6$ & $97.0 \pm 10.3$ & $102.0 \pm 14.7$ & $110.5 \pm 11.1$ \\
\hline Ileum mucosa density $(\mathrm{mg} / \mathrm{cm})$ & $228.9 \pm 18.8$ & $208.0 \pm 16.9$ & $227.0 \pm 15.6$ & $203.2 \pm 21.1$ & $197.9 \pm 19.0$ & $209.8 \pm 16.9$ \\
\hline Colon length $(\mathrm{cm} / \mathrm{kg} \mathrm{BW})$ & $22.3 \pm 1.8$ & $23.9 \pm 1.0$ & $25.6 \pm 1.0$ & $25.4 \pm 1.2$ & $31.7 \pm 2.6^{*}$ & $28.6 \pm 1.2 *$ \\
\hline Colon weight (g/kg BW) & $11.4 \pm 0.7$ & $13.2 \pm 1.9$ & $18.2 \pm 1.0^{*}$ & $12.7 \pm 0.8$ & $18.0 \pm 0.6^{*}$ & $15.0 \pm 1.9$ \\
\hline
\end{tabular}

Values are mean \pm SEM.

* Different $(p<0.05)$ from MF within the same group (NBW or LBW). n.d., not determined.

\section{RESULTS}

Piglet growth and GI tract organ characteristics. There was no significant difference in the daily weight gain between HP and MF piglets, irrespective of the birth weight group (Table 2). AP piglets were offered the same level of energy during that period (Table 2), but their weight gain was lower than that of MF piglets (Table 2). Formula feeding had no impact on stomach relative weight of NBW and LBW piglets (Table 2). The relative weight of the pancreas was greater in HP LBW piglets compared with MF or AP LBW piglets but was not influenced by the type of diet in NBW piglets (Table 2). The liver relative weight was greater in both NBW and LBW formula-fed compared with MF piglets (Table 2). Similarly, small intestine relative length and weight were greater in formula-fed piglets compared with MF ones, irrespective of the type of formula (Table 2). This was predominantly because of an increase in the jejunum mucosa density (weight by unit of length), especially in HP piglets (Table 2). Colon-relative weight was higher in AP fed NBW piglets (Table 2). In LBW piglets, colon length was greater in formula-fed piglets, irrespective of the type of formula (Table 2).

Small intestine structural and functional characteristics. Formula feeding induced an increase in villous length in both the jejunum and ileum of NBW (Fig. $1 A$ and $C$ ) and LBW piglets (Fig. $1 B$ and $D$ ). This effect was more pronounced in the jejunum of LBW piglets $(+49$ and $+56 \%$ for HP and AP, respectively, compared with MF piglets; $p<0.05$ ) than in that of NBW piglets $(+13$ and $+16 \%$ for HP and AP, respectively, compared with MF piglets; $p<0.05)$. In the ileum, the formula-induced increase in villous length was similar in NBW and LBW piglets $(+20$ and $+39 \%$ for HP and AP NBW piglets and +26 and $+39 \%$ in HP and AP LBW piglets compared with similar birth weight MF piglets). Crypt length was little affected by formula feeding, except in the ileum of LBW piglets (Fig. 1D) where it was 23 and $18 \%$ higher in HP and AP, respectively, than in MF LBW piglets.

Aminopeptidase $\mathrm{N}$ activity was increased by formula feeding in the jejunum of NBW piglets but not LBW ones (Table
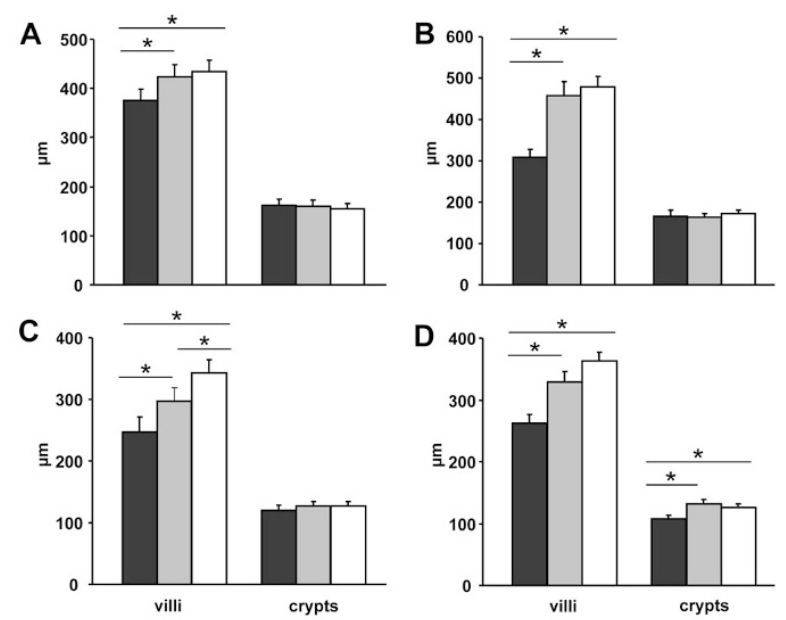

Figure 1. Villous and crypt length in MF and HP or AP formula-fed NBW and LBW piglets. Villous and crypt length was measured in the jejunum of $\mathrm{NBW}(A)$ and LBW $(B)$ piglets and in the ileum of $\mathrm{NBW}(C)$ and LBW $(D)$ piglets. MF, $\square$; HP, $\square$; and AP, $\square$. * ${ }^{*}<0.05$.

3). The activity of this enzyme was not altered by formula feeding in the ileum, irrespective of the piglet birth weight (Table 3). Dipeptidyl-peptidase IV and lactase activities were not influenced by formula feeding at any of the intestinal site (Table 3).

\section{Small intestine permeability and mRNA levels of TJ proteins}

NBW piglets. Formula feeding had no significant effect on jejunal or ileal permeability in NBW piglets (data not shown). Analysis of ZO-1 mRNA expression revealed a lower expression in the jejunum of HP compared with MF NBW piglets $(0.59 \pm 0.07$ versus $0.90 \pm 0.07$, respectively; $p<0.05)$ and a tendency for a lower expression in the ileum of AP compared with MF NBW piglets $(0.65 \pm 0.10$ versus $0.98 \pm 0.13$, respectively; $p=0.08$ ). No effect of the diet was observed for CGN mRNA expression (data not shown).

LBW piglets. Jejunal permeability to HRP was lower in AP LBW piglets compared with MF and HP ones (Fig. 2B). 
Table 3. Proximal jejunum and distal ileum digestive enzymes activities (IU/mg mucosa) in MF and HP or AP-formula fed NBW or LBW piglets

\begin{tabular}{|c|c|c|c|c|c|c|}
\hline & \multicolumn{3}{|c|}{ NBW } & \multicolumn{3}{|c|}{ LBW } \\
\hline & MF & $\mathrm{HP}$ & AP & MF & HP & AP \\
\hline \multicolumn{7}{|l|}{ Jejunum } \\
\hline Lactase & $9.3 \pm 1.8$ & $7.9 \pm 1.3$ & $11.0 \pm 1.2$ & $10.4 \pm 1.4$ & $10.4 \pm 1.5$ & $12.1 \pm 1.0$ \\
\hline Aminopeptidase $\mathrm{N}$ & $7.8 \pm 0.8$ & $10.5 \pm 0.8^{*}$ & $9.9 \pm 0.6^{*}$ & $10.3 \pm 1.3$ & $8.6 \pm 1.0$ & $9.1 \pm 0.9$ \\
\hline Dipeptidy peptidase IV & $1.8 \pm 0.1$ & $1.5 \pm 0.1$ & $1.7 \pm 0.1$ & $2.0 \pm 0.2$ & $2.1 \pm 0.2$ & $1.7 \pm 0.8$ \\
\hline \multicolumn{7}{|l|}{ Ileum } \\
\hline Lactase & $0.7 \pm 0.2$ & $1.1 \pm 0.4$ & $1.0 \pm 0.3$ & $1.3 \pm 0.3$ & $2.7 \pm 1.1$ & $1.6 \pm 0.4$ \\
\hline Aminopeptidase N & $11.5 \pm 2.0$ & $12.2 \pm 1.0$ & $10.7 \pm 0.7$ & $11.7 \pm 0.7$ & $10.7 \pm 1.3$ & $11.7 \pm 1.1$ \\
\hline Dipeptidy peptidase IV & $2.7 \pm 0.4$ & $3.7 \pm 0.5$ & $3.6 \pm 0.4$ & $3.3 \pm 0.2$ & $4.4 \pm 1.1$ & $3.9 \pm 0.4$ \\
\hline
\end{tabular}

Values are mean \pm SEM.

* Different $(p<0.05)$ from MF piglets within the same group (NBW or LBW).

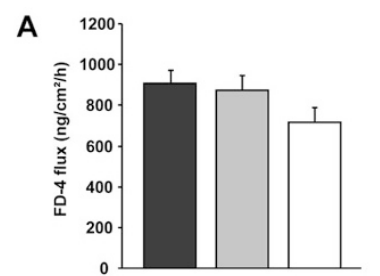

C
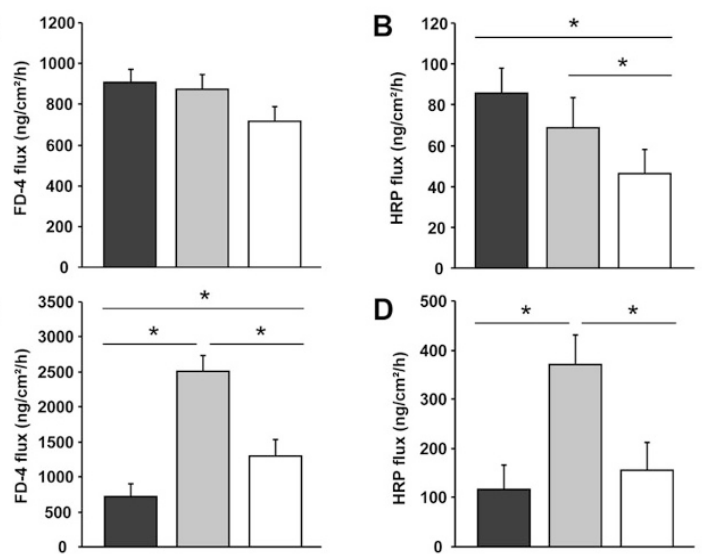

Figure 2. Jejunal and ileal permeability of MF and HP or AP formula-fed LBW piglets. Ex vivo jejunal permeability to FD-4 $(A)$ and $\mathrm{HRP}(B)$ and ileal permeability to FD-4 $(C)$ and HRP $(D)$ were measured in Ussing chambers. MF, $\square$; HP, $\square$; and AP, $\square .{ }^{*} p<0.05$.

Jejunal permeability to FD-4 tended to be also lower in AP formula feeding $(p=0.08$ compared with MF piglets and $p=$ 0.09 compared with HP piglets; Fig. $2 A$ ). On the contrary, in the ileum, HP formula feeding had a dramatic impact on permeability that was $206 \%$ (permeability to FD-4; Fig. 2C) and $219 \%$ (permeability to HRP; Fig. $2 D$ ) higher than that of MF piglets. Lowering the protein content of the formula restored ileal permeability of LBW piglets to value closer to that of MF animals (permeability to FD-4 increased by $83 \%$ compared with MF piglets and permeability to HRP significantly different from that of MF piglets, Fig. $2 C$ and $D$ ). CGN and ZO1 mRNA analysis revealed no effect of the diet on their expression, except a tendency for an increased CGN level in the ileum of HP compared with MF piglets $(1.01 \pm 0.22$ versus $0.54 \pm 0.04$, respectively; $p=0.07$ ).

Nervous regulation of jejunal and ileal permeability in $\boldsymbol{L} \boldsymbol{B W}$ piglets. Because formula feeding affected only intestinal permeability of LBW piglets, we investigated the nervous regulation of intestinal permeability only on those animals but not NBW ones. In the jejunum of MF LBW piglets, carbachol increased while VIP decreased permeability to FD-4 (Fig. 3A), as described in adult intestine. AP formula feeding did not alter this nervous regulation (Fig. 3A). However, in HP piglets, no significant effect of carbachol or VIP on jejunal permeability was observed (Fig. $3 A$ ), suggesting that HP

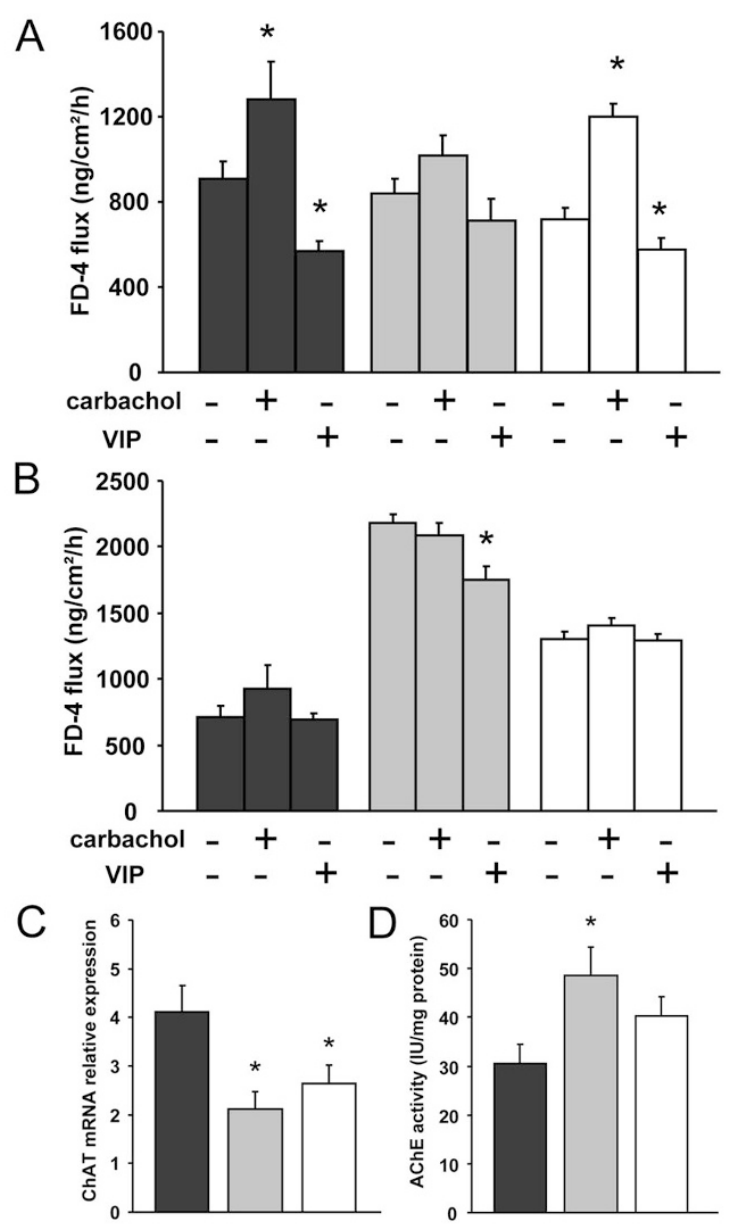

Figure 3. Nervous regulation of jejunal and ileal permeability in MF and HP or AP formula-fed LBW piglets. Jejunal $(A)$ and ileal $(B)$ permeability to FD-4 after addition of $10^{-3} \mathrm{M}$ carbachol (cholinergic agonist) or $10^{-6} \mathrm{M}$ VIP; (C) ChAT mRNA relative expression in the jejunum; and (D) AChE-specific activity in the jejunum. MF, $\square$; HP, $\square$; and AP, $\square$. * $p<0.05$.

formula disturbed jejunal nervous regulation. In the ileum, cholinergic and VIPergic nervous regulation did not seem established yet in MF piglets because no change in permeability were observed in response to carbachol or VIP (Fig. $3 B)$. AP formula feeding did not modify this absence of nervous regulation (Fig. $3 B$ ). However, the ileum of HP piglets displayed a decrease $(-20 \% ; p<0.05)$ of permeabil- 
ity in response to VIP (Fig. 3B), suggesting disturbances in the normal postnatal development of ileal nervous regulation.

To further investigate the default of response to cholinergic stimulation, we studied mRNA expression of ChAT and the activity of AChE, two enzymes involved in acetylcholine metabolism. ChAT mRNA expression was down-regulated in the jejunum of formula-fed animals, irrespective of the type of formula (Fig. 3C). AChE-specific activity was $60 \%$ higher in the jejunum of HP piglets compared with that of MF piglets (Fig. 3D). AChE activity in the jejunum of AP piglets was not different from that of MF piglets (Fig. 3D).

\section{DISCUSSION}

The objective of our study was to evaluate the effect of the level of protein in milk formula on intestinal structure and permeability in NBW and LBW piglets. Although formula feeding compared with mother milk suckling impacted intestinal structure in NBW piglets, this was independent from of the level of protein content in the milk formula per se. However, in LBW piglets, formula feeding with a HP formula sharply increased ileal permeability and disturbed intestinal nervous regulation. Lowering the protein content of the formula clearly reduced these phenomena.

There are many evidence that formula feeding has a trophic effect on the intestine and induces precocious maturation of intestinal disaccharidase activity compared with breast feeding, both in humans and in animal models $(6,7)$. Our present data also show a trophic effect of formula feeding compared with breast feeding but few effect on digestive enzyme activity. This trophic effect of formula feeding was similar in NBW and LBW piglets. Moreover, lowering the protein content of the formula did not modify this response or even enhanced the trophic effect of formula feeding (longer villi in the ileum of NBW piglets fed the AP than the HP formula), suggesting that it was formula feeding rather than the formula protein content that induced this phenomenon. This was also observed in rats where artificial feeding with cow's milk-based or soy proteinbased formula resulted in the same trophic effect (7). The only effect of the composition of the formula in rat was observed with formula differing in the casein to whey protein ratio: the higher this ratio, the higher the trophic effect (23), but our milk formulas were designed to keep the casein to whey ratio constant and similar to that of sow milk. Difference in intestinal structure could be explained by a difference in feed intake. The AP piglets had indeed a lower growth rate than MF ones but the energy intake was similar to that of HP piglets. Moreover, a reduced feed intake is often associated with intestinal hypotrophy (24) than hypertrophy as observed in our animals. Finally, the presence of exogenous dietary components or the absence of factors normally present in maternal milk rather than the artificial procedure of feeding itself seems involved in the trophic effect of formula feeding because artificial feeding with expressed rat milk did not induce changes in intestinal characteristics compared with MF rats (8). Similarly, in 28-d-old piglets, artificial feeding with sow milk slightly reduced jejunal villi by $10 \%$ within $4 \mathrm{~d}$, but no more effect was observed after $7 \mathrm{~d}(25)$.
Measurement of intestinal permeability either in vivo in human neonates or ex vivo in animal models consistently reveals a higher permeability in formula-fed compared with breast-fed neonates $(11,13)$. In our experiment, NBW animal intestinal permeability was poorly affected by formula feeding. However, in agreement with the hyperpermeability observed in formula-fed infants or animals, the ileal permeability of LBW piglets was drastically increased by HP formula feeding. Lowering the protein level of the formula lowered intestinal permeability in LBW piglets: it reduced the permeability to lower levels than the MF animals in the jejunum and reduced the hyperpermeability induced by HP formula feeding in the ileum. The reason of such a decrease is unclear. Different supplementations of formulas (prebiotics, nucleotides, and polyunsaturated fatty acids) did not reduce in vivo intestinal permeability toward that of breast-fed infants in human neonates (26). Similarly, cow's milk-based and soy protein-based formula induced the same hyperpermeability of the intestine in weanling rats (14). Difference in villi and crypt surface could account for by the difference in permeability. However, it is difficult to estimate the actual surface of the mucosa from morphometric data because the density of villi and crypt will also influence mucosal surface. Moreover, this would not explain the reduced permeability in AP LBW piglets compared with HP ones despite a similar increase in villi length. The analysis of TJ protein expression did not give more information about mechanisms involved because mRNA levels of ZO-1 and CGN did not correlate with the paracellular permeability (FD-4) variations. However, interpreting variations in ZO-1 mRNA expression in tissues is not as clear as in cell cultures because several authors have already observed variations in ZO-1 mRNA expression but no difference in ex vivo permeability in rats (27) or increase in ileal permeability but increase in ZO-1 mRNA expression (28). Similarly, it is difficult to predict the actual effect of the tendency for upregulation of CGN mRNA in the ileum of HP LBW piglets from the literature. Indeed, CGN knockdown in MDCK cells up-regulates claudin-2 and ZO-3 expression and increases cell proliferation and monolayer density at confluence (29). However, overexpression of either full-length CGN or its domains does not significantly affect TJ protein levels, the organization and function of TJ, or gene expression or cell density in the same model (30). Finally, it is often alterations of TJ proteins position within the TJ itself that seems to alter intestinal permeability rather than expression of the protein.

Our data demonstrated that HP formula feeding in LBW piglets modified cholinergic and VIPergic regulation of permeability. Indeed, the jejunum of HP piglets did not respond to carbachol (cholinergic agonist) or VIP as opposed to MF and AP piglets while in the ileum they did respond to VIP when MF and AP piglets did not. Such reduced response of the gut to cholinergic stimulation has been observed in various cases of gut dysfunction: electrolyte secretion in response to cholinomimetics was reduced in mice with $\mathrm{T}$ cell-driven enteropathies or rats infected with nematodes as a model of colitis (31); the smooth muscle contractile response to cholinergic stimulation was also reduced in the inflamed intestine (32). In the former study, altered acetylcholine metabolism 
(increase $\mathrm{AChE}$ expression and activity, decreased packaging and exocytosis of acetylcholine, alteration of ChAT expression...) was involved (31). Similarly, many studies reported a decrease in VIP-immunoreactive neurons during inflammation (33). Further studies are needed to investigate whether alteration of the nervous regulation of permeability is linked to an intestinal inflammatory state.

In conclusion, the level of protein in milk formula did not drastically modify the effect of formula feeding itself on intestinal structure, either in LBW or NBW piglets. However, lowering the protein content of formula reduced the ileal hyperpermeability induced by HP formula feeding toward the response observed in MF LBW piglets. It also restored nervous regulation of intestinal permeability. Whether this effect is directly linked to the higher protein content or also partly to the decrease in fat and carbohydrate content to keep formula energy constant remains to be investigated. However, the immunological consequences of these permeability modifications induced by HP formula feeding warrant further investigations regarding the dual role played by intestinal barrier function on immune system education at that age.

Acknowledgments. We thank our technical staff for technical assistance and also thank Dr. Katherine Macé and Dr. Clara Garcia-Rodenas for fruitful discussion of the results.

\section{REFERENCES}

1. Jost R, Maire JC, Maynard F, Secretin MC 1999 Aspects of whey protein usage in infant nutrition, a brief review. Int J Food Sci Technol 34:533-542

2. Baird J, Fisher D, Lucas P, Kleijnen J, Roberts H, Law C 2005 Being big or growing fast: systematic review of size and growth in infancy and later obesity. BMJ 331:929-931

3. Rolland-Cachera MF, Deheeger M, Akrout M, Bellisle F 1995 Influence of macronutrients on adiposity development: a follow up study of nutrition and growth from 10 months to 8 years of age. Int J Obes Relat Metab Disord 19:573-578

4. Turck D, Grillon C, Lachambre E, Robiliard P, Beck L, Maurin JL, Kempf C, Bernet JP, Marx J, Lebrun F, Van Egroo LD 2006 Adequacy and safety of an infant formula with a protein/energy ratio of $1.8 \mathrm{~g} / 100 \mathrm{kcal}$ and enhanced protein efficiency for term infants during the first 4 months of life. J Pediatr Gastroenterol Nutr 43:364-371

5. Thureen P, Heird WC 2005 Protein and energy requirements of the preterm/low birthweight (LBW) infant. Pediatr Res 57:95R-98R

6. Thompson FM, Catto-Smith AG, Moore D, Davidson G, Cummins AG 1998 Epithelial growth of the small intestine in human infants. J Pediatr Gastroenterol Nutr 26:506-512

7. Yeh KY 1983 Small intestine of artificially reared pups: weight gain and changes in alkaline phosphatase, lactase and sucrase activities during development. J Nutr 113:1489-1495

8. Dvorak B, McWilliam DL, Williams CS, Dominguez JA, Machen NW, McCuskey RS, Philipps AF 2000 Artificial formula induces precocious maturation of the small intestine of artificially reared suckling rats. J Pediatr Gastroenterol Nutr 31:162-169

9. Cameron HL, Perdue MH 2007 Muscarinic acetylcholine receptor activation increases transcellular transport of macromolecules across mouse and human intestinal epithelium in vitro. Neurogastroenterol Motil 19:47-56

10. Neunlist M, Toumi F, Oreschkova T, Denis M, Leborgne J, Laboisse CL, Galmiche JP, Jarry A 2003 Human ENS regulates the intestinal epithelial barrier permeability and a tight junction-associated protein ZO-1 via VIPergic pathways. Am J Physiol Gastrointest Liver Physiol 285:G1028-G1036

11. Catassi C, Bonucci A, Coppa GV, Carlucci A, Giorgi PL 1995 Intestinal permeability changes during the first month: effect of natural versus artificial feeding. J Pediatr Gastroenterol Nutr 21:383-386

12. Weaver LT, Laker MF, Nelson R, Lucas A 1987 Milk feeding and changes in intestinal permeability and morphology in the new born. J Pediatr Gastroenterol Nutr 6:351-358

13. Udall JN, Colony P, Fritze L, Pang K, Trier JS, Walker WA 1981 Development of gastrointestinal mucosal barrier. II. The effect of natural versis artificial feeding on intestinal permeability to macromolecules. Pediatr Res 15:245-249

14. Teichberg S, Isolauri E, Wapnir RA, Roberts B, Lifshitz F 1990 Development of the neonatal rat small intestinal barrier to nonspecific macromolecular absorption: effect of early weaing to artificial diets. Pediatr Res 28:31-37

15. Gebbers JO, Laissue JA 2004 Bacterial translocation in the normal human appendix parallels the development of the local immune system. Ann N Y Acad Sci 1029:337343

16. Urao M, Teitelbaum DH, Drongowski RA, Coran AG 1996 The association of gut-associated lymphoid tissue and bacterial translocation in the newborn rabbit. J Pediatr Surg 31:1482-1487

17. Söderholm JD, Yates DA, Gareau MG, Yang PC, MacQueen G, Perdue MH 2002 Neonatal maternal separation predisposes adult rats to colonic barrier dysfunction in response to mild stress. Am J Physiol Gastrointest Liver Physiol 283:G1257-G1263

18. Barreau F, Ferrier L, Fioramonti J, Bueno L 2004 Neonatal maternal deprivation triggers long-term alterations in colonic epithelial barrier and mucosal immunity in rats. Gut 53:501-506

19. Morise A, Sève B, Macé K, Magliola C, Le Huërou-Luron I, Louveau I 2009 Impact of intra-uterine growth retardation and early protein intake on growth, adipose tissue and the insulin-like growth factor system in piglets. Pediatr Res 65:45-50

20. Marion J, Biernat M, Thomas F, Savary G, Le Breton Y, Zabielski R, Le HuerouLuron I, Le Dividich J 2002 Small intestine growth and morphometry in piglets weaned at 7 days of age. Effects of energy intake. Reprod Nutr Dev 42:339-354

21. Guggi D, Bernkop-Schnürch A 2005 Improved paracellular uptake by the combination of different types of permeation enhancers. Int J Pharm 288:141-150

22. Heyman M, Ducroc R, Desjeux JF, Morgat JL 1982 Horseradish peroxidase transport across adult rabbit jejunum in vitro. Am J Physiol 242:G558-G564

23. Yajima T, Kanno T, Katoku Y, Kuwata T 1998 Gut hypertrophy in response to the ratios of casein and whey protein in milk formulas in artificially reared rat pups. Biol Neonate 74:314-322

24. Pluske JR, Williams IH, Aherne FX 1996 Villous height and crypt depth in piglets in response to increases in the intake of cow's milk after weaning. Anim Sci 62:145-158

25. van Beers-Schreurs HM, Nabuurs MJ, Vellenga L, Kalsbeek-van der Valk HJ, Wensing T, Breukink HJ 1998 Weaning and the weanling diet influence the villous height and crypt depth in the small intestine of pigs and alter the concentrations of short-chain fatty acids in the large intestine and blood. J Nutr 128:947-953

26. Colomé G, Sierra C, Blasco J, Garcia MV, Valverde E, Sanchez E 2007 Intestinal permeability in different feedings in infancy. Acta Paediatr 96:69-72

27. Barrat E, Michel C, Poupeau G, David-Sochard A, Rival M, Pagniez A, Champ M, Darmaun D 2008 Supplementation with galacto-oligosaccharides and inulin increases bacterial translocation in artificially-reared newborn rats. Pediatr Res 64:34-39

28. Hamard A, Mazurais D, Boudry G, Le Huërou-Luron I, Sève B, Le Floc'h N 2009 A moderate threonine deficiency affects gene expression profile, paracellular permeability and glucose absorption capacity in the ileum of piglets. J Nutr Biochem 2010;21:914-921

29. Guillemot L, Citi S 2006 Cingulin regulates claudin-2 expression and cell proliferation through the small GTPase RhoA. Mol Biol Cell 17:3569-3577

30. Paschoud S, Citi S 2008 Inducible overexpression of cingulin in stably transfected MDCK cells does not affect tight junction organization and gene expression. Mol Membr Biol 25:1-13

31. Hirota CL, McKay DM 2006 Cholinergic regulation of epithelial ion transport in the mammalian intestine. Br J Pharmacol 149:463-479

32. Aulí M, Nasser Y, Ho W, Burgueno JF, Keenan CM, Romero C, Sharkey KA, Fernandez E 2008 Neuromuscular changes in a rat model of colitis. Auton Neurosci 141:10-21

33. Sigge W, Wedel T, Kühnel W, Krammer HJ 1998 Morphologic alterations of the enteric nervous system and deficiency of non-adrenergic non-cholinergic inhibitory innervation in neonatal necrotizing enterocolitis. Eur J Pediatr Surg 8:87-94 